\title{
PLANEJAMENTO ESCOLAR EM TEMPOS DE PRECARIZAÇÃO DA EDUCAÇÃO ${ }^{1}$
}

Paulino José Orso ${ }^{2}$

\section{RESUMO}

Este artigo, tem como objeto central de discussão a questão do planejamento escolar, ocupa-se da importância do planejamento, os tipos de planejamento e os elementos constituintes. Parte do pressuposto de que o planejamento está integrado à vida do homem e da sociedade e se faz cada vez mais necessário à realização de todas as atividades humanas, inclusive da educação, tendo em vista a concretização dos objetivos. Mesmo que contemple algumas questões comuns, como por exemplo, a intencionalidade, a deliberação, a articulação de um conjunto de elementos e a ação coordenada de determinados agentes, o planejamento educacional guarda as especificidades próprias do trabalho educativo.

Palavras-chave: Educação; Planejamento Escolar; educação e sociedade.

\section{PLANNING SCHOOL IN TIMES OF EDUCATION PRECARIOUS}

\begin{abstract}
This article has as its central subject of discussion the issue of school planning, deals with the importance of planning, the types of planning and the elements. It assumes that planning is integrated into the life of man and of society and becomes increasingly necessary to the realization of all human activities, including education, with a view to achieving the goals. Even that addresses some common issues, such as intentionality, the resolution, the articulation of a set of elements and the coordinated action of certain agents, educational planning saves the specific nature of educational work.
\end{abstract}

Keywords: Education, School Planning, education and society.

\section{O PLANEJAMENTO E SUA IMPORTÂNCIA}

Este artigo, resultado de pesquisa, trata da questão do planejamento escolar. Partindo da materialidade histórica, procura articular o planejamento escolar ao planejamento em geral. O planejamento está cada vez mais integrado à vida do homem e da sociedade em todas as esferas de sua ação e, consequentemente, também na educação. Entretanto, ao contrário do que parece, não é propriamente produto da modernidade, encontra-se presente desde a antiguidade a partir do momento em que os homens deixam de ser meramente mais um ser da natureza, diferenciam-se dela e são forçados a produzir sua vida de modo intencional e voluntariamente. A partir daí, desde a caça e a defesa, da mesma forma que a sobrevivência dos indivíduos e a educação passam a exigir planejamento. Contudo, ainda que o planejamento pressuponha algumas questões comuns, como por exemplo, a intencionalidade, a deliberação, a articulação de um conjunto de elementos e a ação coordenada de determinados agentes tendo em vista os fins a atingir, 
ele não se faz sempre da mesma forma, assume características únicas em cada época e em cada sociedade em função do acúmulo das experiências, conhecimentos, habilidades humanas e também dos desafios a enfrentar. Assim, também ocorre com o planejamento educacional, que é indispensável ao adequado desenvolvimento das atividades educativas. Todavia, para que seja relevante, pressupõe-se que seja exequível, que parta da realidade concreta e das condições objetivas.

Todavia, para tratar desta questão iniciamos por perguntar: hoje, ainda é possível agirmos e vivermos sem planejar nossas ações? Não. Toda e qualquer coisa que façamos exige cada vez mais ação consciente e planejada. Contudo, muitas delas, fazemo-las, de certa forma, com um "planejamento inconsciente e automático", pois, já se encontram incorporadas à rotina diária e parecem ter sido planejadas anteriormente, ou então o contrário, parecem não terem sido planejadas. Mas, há outras, muitas outras que, ao contrário disso, exigem uma ação cada vez mais deliberada, sistemática e consciente. Depois que o homem primitivo se desenvolveu e adquiriu capacidade reflexiva, as relações sociais tornaram-se complexas, surgiu a necessidade de superar o espontaneísmo, as ações de tipo estímulo $\mathrm{x}$ resposta e, consequentemente, construir a vida social de forma intencional, voluntária e planejada.

Se se quiser obter êxito em determinadas ações, é necessário realizar um planejamento cada vez mais eficiente, aprimorado e preciso referente aquilo que se pretende. Por exemplo: um juiz que preside um julgamento necessita, previamente, prever com bastante precisão todos os passos do processo; um médico que vai realizar uma intervenção cirúrgica necessita acercar-se de todas as precauções para evitar os possíveis riscos à vida; um turista deve prever tudo o que envolve o passeio, para que o mesmo não lhe traga dissabores; um agricultor, ao cultivar sua lavoura, precisa fazer a análise do solo antecipadamente, verificar o tipo de clima, identificar a semente mais adequada, considerar os possíveis riscos (intempéries, pragas, inseticidas, herbicidas, clima...), pensar no tipo de colheita, o transporte, os preços de venda, enfim, os resultados da colheita. Enfim, como se vê, o planejamento não é uma exigência e uma prática exclusiva da educação. Na vida social, de forma intencional ou não, somos forçados a planejar o tempo todo. Isto significa que na educação não é possível se obter êxito sem realizar um planejamento detalhado considerando tudo o que envolve esse processo, sobre o quê, a quem, para quem, como, para quê, onde ocorre, de que forma é realizada, por que meios e em que condições ocorrerá.

Numa sociedade em que o conhecimento também deixou de ser espontâneo e passou a ser uma necessidade social deliberada, não é mais possível fazer educação sem um planejamento detalhado e rigoroso dos passos a serem dados, das ações a serem realizadas, dos objetivos visados, das variáveis que interferem no processo, das estratégias a serem adotadas, considerando a sociedade que se tem e a que se quer construir. A vida social atual, com sua complexidade, requer planejamento. É através dele que o homem organiza e disciplina sua ação, sua vida e a sociedade. É óbvio, porém, que ainda que o planejamento possibilita dominar uma série de variáveis que interferem nos processos, não é possível dominá-las absolutamente. Então, por um lado, significa que o planejamento não garante por si só o êxito das ações, dos projetos. E, por outro, que precisa ser pensado de tal modo que permita fazer adequações durante seu próprio processo de implementação.

Mas então, em que consiste o planejamento? Considerando a realidade sócioeducacional que se tem, consiste num conjunto de ações coordenadas entre si, que concorrem para a obtenção de um determinado resultado, o objetivo que se espera ou 
deseja. Planejamento deve ser compreendido como um guia para a ação. Para isso, deve envolver a previsão dos meios para realizar uma ação; pressupõe uma ação metódica e a racionalização dos meios para a consecução de determinados fins. Planejamento é uma ação sistemática e consciente, que pressupõe a racionalização, a organização e coordenação de um processo, neste caso, do processo ensino e aprendizagem. Ainda que indispensável à prática docente, não pode e nem deve ser confundido como uma fórmula mágica para a obtenção de resultados.

O planejamento é uma ação transitiva, que liga a realidade existente à realidade que se quer construir. O planejamento, de certa forma, é uma espécie de antecipação da realidade. O ato de planejar leva o agente que o elabora a se transportar para o futuro, isto é, a visualizar o resultado final que se espera obter antes mesmo que ele ocorra e este o remete para o presente, para então, de posse do passado e da realidade atual, por em ação o processo a ser construído, ou seja, construir o futuro.

O processo de planejar é um ato que envolve dois momentos articulados entre si. Um é o da elaboração, da racionalização, da antecipação dos possíveis resultados e o outro é o da operacionalização, da colocação do plano em ação, da realização. Uma observação importante a se fazer é que a execução não deve ser compreendida como adaptação ou transposição mecânica de uma etapa a outra, como se o plano fosse uma espécie de carimbo que se aplica, que se imprime em todos os lugares da mesma forma. O plano não deve ser compreendido como imutável, definitivo, pronto e acabado, mas sim como um indicativo, um referencial que pode estar sujeito a mudanças, adequações e alterações, se assim a realidade exigir.

Para que um planejamento se transforme, efetivamente, num guia que oriente e direcione a ação e o trabalho, deve conter as diretrizes e os meios para a realização do mesmo. Não deve ser um plano autoritário. Como guia, não deve ser tão rígido de modo que impeça de realizar modificações e adequações quando necessárias, nem tão flexível que permita que se faça qualquer coisa, de qualquer modo. Pois, em ambas as situações, o planejamento se tornaria inútil. Assim, o detalhamento dos conteúdos, das ações, dos objetivos deve ser organizado de forma seqüencial e progressiva, permitindo que aquilo que for trabalhado anteriormente sirva de apoio para a realização de novas aprendizagens, ou então, para que o desenvolvimento real atingido em cada momento potencialize a realização de outros passos. Além disso, o planejamento deve ser objetivo, isto é, deve prever as ações possíveis de serem realizadas em cada uma das etapas de seu desenvolvimento. Enfim, deve ser coerente e flexível. Coerente no sentido de haver unidade entre os objetivos gerais, os específicos, os conteúdos, o método, as estratégias ou metodologias e a avaliação. Ou seja, os elementos do plano devem estar articulados entre si. Deve ser flexível para permitir adequações e mudanças sempre que a realidade assim o suscitar.

\section{O PLANEJAMENTO DE AULA, SUAS ARTICULAÇÕES E A RELAÇÃO ENTRE ESCOLA E SOCIEDADE}

Quando nos propomos a refletir sobre esta questão ou dizer em que consiste o Plano de Aula ou o plano de trabalho docente, vem à tona outras questões, como por exemplo: é possível ater-se pura e simplesmente neste plano, na relação entre um professor e seus alunos, como geralmente ocorre? É possível pensar e realizar um planejamento escolar sem considerar o mundo e a sociedade em que a escola/nós estamos inseridos? É possível fazer 
um planejamento sem ter presente uma concepção de homem, de sociedade e de mundo que se quer construir?

Será que para fazer um planejamento escolar ou um plano de ensino ou de aula é preciso ter presente, considerar e responder antecipadamente tantas questões? Não basta ir para a sala de aula fazer o trabalho e ponto final? Em geral, o professor organiza a aula, as atividades para um determinado dia ou para alguns dias, vai para a escola/sala de aula e procura colocar em prática o plano traçado. Contudo, precisamos nos perguntar: Afinal de contas, quem é o professor e como concebemos os alunos? Isto, porém, também não é suficiente. É preciso perguntar: o que é, ou em que consiste a educação? Contudo, isto também, ainda não é suficiente, é preciso perguntar: afinal, que sociedade é esta, como funciona a sociedade na qual fazemos educação? Tantas perguntas... Mas, vamos começar por fazer o caminho de volta.

Talvez, para quem esteja lendo ou ouvindo estas, que parecem ser perguntas infindáveis e, por vezes, enfadonhas e desnecessárias, isto não passe de uma série de questões "sem pé nem cabeça", uma forma de escamotear e de desviar a atenção da questão central - o trabalho docente que se executa no interior da sala de aula. Mas, com um pouco de paciência, talvez passe a considerar isso tudo de outro modo.

De fato, a questão central é dar conta de elaborar o planejamento de uma boa aula, de organizar os conteúdos, os procedimentos e as estratégias de ensino, de tal forma que os alunos assimilem aquilo que é trabalhado e que, além do mais, consigam realizar uma aprendizagem significativa que não se limite a decorar, incorporar, introjetar, engolir aquilo que o professor ensina, mas se apropriar daquilo que for ensinado para que sirva de base para realizar por si novas aprendizagens, ou seja, que o professor ajude o aluno a construir sua autonomia cognitiva. Caso contrário, se a formação for de outro modo, por exemplo, se o professor se limitar a transmitir informações, dados e conteúdos estanques, e se o aluno se limitar a apreender isso, a aprendizagem acabará no dia em que ele sair da escola, seja em que nível for.

Então, por ora, retomemos uma das questões postas acima. Em que consiste a educação? Esta questão, por sua vez, remete a outra, qual seja, a educação se limita à escola? Para não responder perguntando novamente, podemos dizer que a escola é um espaço específico de educação, a educação escolar. Mas, há uma infinidade de outras formas de se educar, por uma infinidade de outros meios. Por exemplo, podemos citar a educação que é realizada na família, no trabalho, nos sindicatos, nas associações, na igreja, na rua, a educação realizada pela burocracia, pelos meios de comunicação etc. Isto se pode denominar de educação não-formal ou de educação informal, não escolar. Contudo, este tipo de educação não dá conta das necessidades da sociedade atual.

Esta afirmação indica que não se pode pensar na educação sem a sociedade. Mas, afinal de contas, porque é que não podemos nos preocupar somente com a escola, com a sala de aula? Porque é que, ao fazermos nosso trabalho na escola e na sala de aula, temos que nos preocupar com a sociedade na qual estamos inseridos? Simplesmente porque não há escola, assim como não há educação e nem ensino sem a sociedade. Então, ao fazermos educação, ao nos ocuparmos do ensino, é necessário considerar a sociedade em que estamos inseridos, pois a escola faz parte dela, está na sociedade e, em grande medida, "reflete" o estágio de desenvolvimento e o nível das relações sociais de cada momento, como veremos mais adiante. E, não poderia ser diferente uma vez que a escola e a aprendizagem não é um ente, nem são relações que ocorrem isoladamente. Os alunos e os professores constituem a própria sociedade; os conteúdos são produzidos na e pela 
sociedade; as condições da escola e do ensino são marcadas pela sociedade. Enfim, a educação não se constitui num trabalho simples que se limita à relação professor/aluno no interior de quatro paredes; constitui-se numa relação complexa na qual múltiplos determinantes sociais, econômicos, culturais, históricos e políticos interferem.

Se a escola está marcada pelas relações e condições sociais de cada memento, também se pode dizer que a educação tem a ver com a forma como a sociedade prepara os indivíduos, por meio das suas diversas formas, para viverem nela mesma. Uma das formas utilizadas para isso é a educação informal, da qual não vamos nos ocupar aqui para além daquilo que já falamos acima. Outra é a educação formal, a educação escolar, que é nosso principal objeto de análise e que nos ocuparemos adiante.

Como dissemos anteriormente, ao fazer educação, não podemos desconsiderar a sociedade mais ampla, pois é ela que nos fornece os conteúdos, os meios, as formas, as condições e, inclusive, dita os fins para que ela ocorra. Isto significa que, em última instância, quem de fato educa é a sociedade, mediada por pessoas, conteúdos, coisas, condições e meios. Ou seja, a sociedade se constitui no começo, no meio e no fim da educação. Mas, que sociedade é essa que nos educa e para a qual ela própria educa? É uma sociedade fundada na propriedade privada dos meios de produção, organizada em classes antagônicas, que tem como lei a concorrência, a competição e a exploração do homem pelo homem.

Em consequência disso temos uma sociedade diferenciada, heterogênea, desigual, permeada por problemas como a violência, as guerras, a fome, o analfabetismo, problemas de aprendizagem etc. No fundo, a educação desenvolvida no interior desta sociedade, como mencionamos, em termos gerais, "reflete" estas condições e responde às necessidades de reprodução desta sociedade. Portanto, a educação que temos e que fazemos, tanto aquela que ocorre informalmente, quanto a desenvolvida na escola, no geral, é a educação possibilitada por esta sociedade, segundo o grau de criticidade e de desenvolvimento técnico e científico que ela permite em cada momento e em cada lugar. Nesta perspectiva, Paulo Freire (1975, p. 30) diz que "não é a educação que forma a sociedade de uma determinada maneira, senão que esta, tendo-se formado a si mesma de uma certa forma, estabelece a educação que está de acordo com os valores que guiam essa sociedade".

Mas, porque não podemos simplesmente desenvolver nosso trabalho no interior da sala de aula, na escola sem nos preocupar com a realidade mais ampla, se é a sociedade que, em última instância, determina a educação? Porque, caso continuemos fazendo isso, também continuaremos colaborando para simplesmente reproduzir essas condições, as condições em que vivemos e, se não fizermos nada de diferente, também não podemos reclamar, pois, no mínimo seria um contra-senso criticar aquilo que nós mesmos fazemos, ou então, deveríamos nos colocar em questão e criticar a nós mesmos. Como certamente não concordamos e estamos insatisfeitos com as condições em que vivemos, darmo-nos por satisfeitos em simplesmente reproduzir essas condições, no mínimo, constitui-se num absurdo. Por outro lado, também seria absurdo compreender a realidade, a sociedade e o mundo em que se está inserido e não fazer nada para transformá-los. Ou seja, não resta outro caminho senão empenhar-se em compreender cada vez melhor o homem, a sociedade, o mundo e a educação e fazer desta um instrumento de conhecimento, aprendizagem, ação e transformação.

A educação formal, escolar, nem sempre existiu. Surgiu durante o escravismo, marcada pelos antagonismos entre as classes e, por um longo tempo, basicamente até o 
final da Idade Média, ela tem sido um privilégio das classes dominantes, tanto em termos de acesso, quanto em relação aos benefícios gerados por ela. Contundo, a partir da modernidade, com o surgimento do protestantismo, com o crescimento da burguesia e o desenvolvimento da sociedade industrial, a escola passou a ser uma necessidade social, tanto para a burguesia, quanto para os trabalhadores que precisavam de braços "iluminados" para o trabalho, ou seja, o novo modo de produzir a vida social demandava de força de trabalho com um mínimo de conhecimento técnico e científico para dar conta da manipulação dos novos instrumentos de produção. Com isso, a escola começa a se popularizar. E a mesma coisa acontece com o professor. Ou seja, a partir da modernidade, a escola, que também supõe a existência do professor, tornou-se uma necessidade social, e passou a exercer uma função social específica. Isto, porém, não eliminou o caráter de classe que permeia a educação. Ainda hoje ela continua com esta marca, assim como continua a contribuir para a geração de todos os subprodutos típicos desta sociedade, como vimos acima.

Retomando: se a educação consiste na preparação dos indivíduos pela sociedade (por meio dos indivíduos e das condições) para viverem na própria sociedade e, se a escola tornou-se uma necessidade social, qual a função que cabe à escola e ao professor? Cabe a ele, como uma espécie de delegado da sociedade, alguém que, por via da sociedade, da escola, por meio de cursos e concursos, lhe é reconhecida a capacidade e lhe é confiada a tarefa de educar, de ensinar às novas gerações e de prepará-las para viverem na própria sociedade.

Isto, contudo, não significa que a educação deve se limitar à transmissão de conteúdos, tidos como se fossem neutros, isentos, despretensiosos. Por outro lado, não significa que deve desconsiderá-los. Também não significa que ela deve pura e simplesmente adequar os indivíduos à sociedade em que vivem. Pelo contrário. Uma vez reconhecida a sociedade, sua forma de funcionamento, de organização e de produção, o professor, a escola, a educação devem contribuir para o desvelamento das contradições que a permeiam e, por meio da forma e do conteúdo a ser ensinado, contribuir para a transformação da mesma. Neste sentido, a educação não pode ser entendida de outra forma senão como atividade revolucionária e, como ela não acontece sem o educador, para que adquira este caráter, cabe a este ser revolucionário, e fazê-la de forma revolucionária.

A sociedade centralizada, hierárquica, especializada, elitista e seletiva como está organizada atualmente, bloqueia, cerceia e inibe as iniciativas que possam desafiá-la e pôla em questão. Nesse sentido, nos remetemos a uma citação de Harper, que gosto muito, que diz:

é certo, porém, que estas experiências, ao aproveitarem as brechas existentes e ao utilizarem os espaços disponíveis, esgotam o campo do possível no interior do sistema escolar. Os educadores, os pais de alunos e os estudantes que conseguirem criar esses espaços de liberdade e de experimentação fazem de sua prática educativa uma negação vivia do modo de organização social dominante e do tipo de escola seletiva e elitista que lhe é funcional (19870, p. 116).

O professor realiza um trabalho social específico, não melhor, nem mais nobre ou superior, mas sim diferente dos demais trabalhadores; o professor não é um sacerdote; deve ser entendido como um profissional. Se não fosse professor, como um trabalhador que precisa vender sua força de trabalho para poder sobreviver, possivelmente estaria realizando um outro trabalho qualquer e vendendo sua força como padeiro, marceneiro, 
agricultor, confeiteiro, vendedor, pedreiro, coveiro, escriturário, motorista etc. Ou seja, seria membro da classe trabalhadora de qualquer modo, submetido à mesma lógica do modo de produção capitalista como os demais trabalhadores, ainda que exercendo uma outra função social. Muitas vezes, pelo fato de o professor trabalhar com as ideias, tem a impressão de que não é trabalhador, de que não pertence à mesma classe dos demais. Daí a importância de se reconhecer como trabalhador, como membro da mesma classe, com a "missão" de, por intermédio do trabalho que realiza, contribuir para a superação de sua própria condição social.

Enfim, o professor é um trabalhador que se especializou na arte de ensinar/aprender e, assim como os demais trabalhadores, deve realizar seu trabalho da melhor maneira possível. Para isso, não pode se dar o luxo de fazê-lo de qualquer jeito, confiar apenas na sua experiência, nos seus anos de trabalho, na sua própria sorte. O professor não deve pensar que tudo está sabido e que não mais precisa estudar; deve ser um estudioso; deve estar em busca de aperfeiçoamento constante; deve acompanhar as transformações que vão acontecendo na escola, na sociedade local, como também as que acontecem na política, na economia, na geopolítica, enfim, as mudanças que vão ocorrendo no mundo, a todo momento.

Vimos que a educação é um trabalho complexo que não se limita a uma relação entre professor e aluno. É uma relação entre professores e alunos mediados pelas condições e relações sociais de cada momento e de cada sociedade, sem esquecer, porém, da totalidade das relações nas quais o professor, o aluno e a escola estão inseridos. Neste sentido, a realização de um trabalho bem feito no interior de uma sala de aula, numa escola, exige e pressupõe a compreensão das inter-relações e das articulações entre as várias dimensões que o trabalho está envolvido. Isto, todavia, requer estudo, pesquisa e planejamento.

O plano de trabalho docente, apesar de ser o objeto central de nossa preocupação deste texto, de acordo com o raciocínio desenvolvido até aqui, não deve ser compreendido como algo isolado e fechado em si mesmo. A ele articulam-se os Planos de Ensino, a Proposta (plano) Curricular, o Plano Municipal (PME), Plano Estadual (PEE), o Plano Nacional de Educação (PNE) e até mesmo o Plano Internacional (orientado pela UNESCO). Contudo, de acordo com uma compreensão mais adequada, nem se poderia propriamente falar de um PME ou em um PEE. É ridículo se falar de um plano desse tipo. $\mathrm{Na}$ verdade, um verdadeiro projeto de educação não deveria voltar-se para uma nação, um estado, um município ou uma escola, mesmo que seja lá que ele esteja alicerçado e se realize concretamente. Deveria, isto sim, estar direcionado para a formação de um determinado tipo de homem, para uma determinada forma de organização e de produção da vida social, ainda que isto ganhasse contornos e características de acordo com determinados locais, condições e épocas. Dentro desta perspectiva, o trabalho que se executa no interior de uma sala, de uma escola, não pode fechar-se em si mesmo, deve ter presente o tipo de homem e de sociedade que se tem e o tipo de homem e de sociedade que se quer construir.

Neste sentido, ao mesmo tempo, o planejamento deve considerar os conteúdos, as formas de ensino a ser realizadas na escola, a sociedade que se tem e a que se pretende construir, os objetivos visados e os meios através dos quais se pretende atingir. Por isso, não é um trabalho simples e nem pode realizar-se de qualquer modo. Vejamos qual é a especificidade de cada um dos planos? 


\section{PLANOS EDUCACIONAIS}

\section{PLANO DE TRABALHO DOCENTE}

A aula é uma relação interacional por meio da qual se realiza o processo de ensino eaprendizagem; é o detalhamento do plano de ensino com a definição das atividades, dos conteúdos, das ações, das formas, dos meios e dos objetivos que envolvem uma determinada unidade de ensino. Os temas, as subunidades, os tópicos previstos no plano de ensino ganham aqui o detalhamento para o trabalho de cada dia ou para um conjunto de aulas. Através dos planos de aula são organizadas e criadas as situações de ensino e de aprendizagem. Os planos de aula individuais planejados para cada dia do ano, que contam sempre com conteúdo, formas, estratégias/metodologias e objetivos geral e específicos, ao final, constituem-se numa unidade que é o plano de ensino de cada área ou disciplina de um determinado ano ou etapa de aprendizagem.

\section{PLANO DE ENSINO}

O plano de ensino, por sua vez, é o detalhamento do plano curricular. É um documento no qual são relacionadas e estabelecidas as atividades, os conteúdos, as ações, as formas, os meios e os objetivos que envolvem uma determinada área de conhecimento, ou uma disciplina específica que compõe o currículo, ou então, a proposta político pedagógica (PPP) de uma determinada escola. No caso dos planos de ensino elaborados pelos docentes individualmente, da mesma forma que no plano de trabalho docente, apesar de parecer como se fossem ações isoladas, atos decididos e deliberados por um professor específico, ao final, devem ter presente que cada um, na verdade, constitui-se "numa parte de um determinado todo", que é a Proposta Político Pedagógica de cada escala. Sim, de cada escola. Pois, cada escola tem sua realidade, seu contexto, seus alunos, seus professores, suas condições, que exigem um PPP específico para dar conta dessa realidade, ainda que tenha alguns elementos comuns aos dos PPPs de outras escolas situadas num determinado território. O plano de ensino é a previsão dos objetivos e tarefas do trabalho docente para um ano ou semestre, conforme for organizado o currículo escolar.

\section{PROJETO POLÍTICO PEDAGÓGICO (PPP)}

O Projeto Político Pedagógico pode receber diversos nomes, tais como, Proposta Curricular, Currículo escolar ou Plano de Escola. A Proposta Político Pedagógica é um documento no qual consta o detalhamento de todas as atividades, os conteúdos, as ações, os objetivos, as formas, os meios e as concepções de todo o trabalho a ser desenvolvido por uma determinada escola, durante um determinado período. O PPP é um documento que expressa, de forma mais ou menos sintética, as orientações mais gerais ou globais de uma escola. O PPP, por um lado, faz a ligação da escola com o sistema(s) educacional(is) e, de outro, com os planos de ensino individuais de cada docente.

De acordo com José Carlos Libâneo (1994, p. 23), o PPP, que denomina o PPP de plano de escola,

é o plano pedagógico e administrativo da unidade escolar, onde se explicita a concepção pedagógica do corpo docente, as bases teóricometodológicas da organização didática, a contextualização social, econômica, política e cultural da escola, a caracterização da clientela 
escolar, os objetivos educacionais gerais, a estrutura curricular, as diretrizes metodológicas gerais, o sistema de avaliação do plano, a estrutura organizacional e administrativa.

À despeito de haver diversas iniciativas, sobretudo por parte de governos, com a finalidade de retirar do nome da Proposta Pedagógica o caráter político, induzindo que a preocupação do professor, dos alunos, da escola e da educação deve se restringir ao interior da escola, não resta dúvida de que a denominação Projeto Político Pedagógico é o que melhor expressa o alcance, as dimensões e a abrangência do currículo escolar em função de que, simultaneamente, indica que uma escola não tem apenas que se preocupar com uma proposta pedagógica, estritamente falando, mas também necessita se preocupar com a dimensão política e ideológica da proposta que está sendo elaborada. Noutras palavras, significa que, ao fazer educação, é necessário se preocupar com o mundo no qual a educação se faz. Isto implica dizer que o conhecimento e o trabalho que se realiza não são neutros, que carregam implicações sociais, culturais, políticas, econômicas e ideológicas. Pois, como diz um determinado autor, se expulsarmos a verdadeira filosofia pela porta da frente, entram, semiconscientemente, talvez, pela porta dos fundos, os preconceitos tacanhos e de classe. Por isso, neste mesmo sentido, diria Álvaro Vieira Pinto, é necessário verificar as implicações sociais do trabalho que executamos.

Ainda que cada escola elabore o seu PPP, no conjunto, os diversos PPPs também devem expressar o Plano Municipal de Educação (PME), com sua concepção de homem, de mundo, de sociedade, os conteúdos, as formas, os meios e os objetivos pretendidos por um determinado grupo ou sociedade. Da mesma forma que, congregados, os PMEs deveriam constituir os PEE e estes, articulados entre si, expressar o PNE, que por sua vez, deveria orientar a educação para a formação de uma determinada concepção de homem e sociedade. Claro que os diversos planos, nas diferentes esferas, carregam consigo determinados objetivos e fins. Todavia, a partir de uma nova concepção de educação, o que se tem em mente é a construção de uma nova sociedade.

Assim, ao se fazer os diversos planos, nas suas diversas dimensões, não podemos esquecer que eles não existiriam sozinhos e isolados, que são elementos particulares, mas que dizem respeito à universalidade e que a todo momento devem ser compreendidos $\mathrm{e}$ referir-se à relação todo / parte, particular / universal.

\section{PLANO MUNICIPAL, PLANO ESTADUAL E PLANO NACIONAL DE EDUCAÇÃO}

Estes três planos educacionais expressam, cada um no seu âmbito de abrangência, mas articulados entre si, o detalhamento do que um determinado grupo, um segmento social ou uma sociedade pensa, quer e pretende fazer da educação sob sua responsabilidade. É a explicitação das diretrizes, das metas, da concepção de educação, do que se pretende realizar, das atividades, dos conteúdos, das ações, dos objetivos, das formas e dos meios que nortearão a educação durante um determinado período, envolvendo os diversos níveis, modalidades e programas relacionados a ela.

Todos estes planos, que vão desde o plano de trabalho docente, o de ensino, o PPP, o PME, o PEE e o PNE, deve / deveriam estar articulados entre si. Digamos que se se tivesse clareza do projeto de educação que se quer, não apenas para um país, estado, município ou para uma escola, mas sim, de um projeto de homem e de sociedade, ficaria fácil de compreender e traçar as metas, as ações, os objetivos, os conteúdos, os meios, as formas para que, em cada local ou âmbito de responsabilidade e abrangência, deveríamos 
implementar para concretizar a sociedade que pretendemos. Digamos ainda que o plano de trabalho docente é a extensão e a realização do plano de ensino, e estes, a realização do PPP que, por sua vez, é a realização dos PME, PEE e PNE, noutras palavras, a realização da sociedade que se quer.

\section{ELEMENTOS QUE ENVOLVEM O PLANEJAMENTO EM GERAL E O PLANO DE AULA EM PARTICULAR}

A preparação, o planejamento da aula, bem como do plano de ensino e do PPP da escola é uma tarefa importantíssima e indispensável para todo e qualquer professor e para a escola que se propõe a realizar um trabalho sério e responsável. Os planos e propostas devem ser expressos na forma escrita, revelado num determinado documento, tanto para possibilitar as necessárias e constantes revisões e aperfeiçoamento (a dada momento) de ano a ano, mas também para acumular experiências, ir percebendo as mudanças que vão ocorrendo ao longo do tempo, possibilitar uma reflexão mais apurada e agir sobre eles para melhorá-los constantemente.

Como vimos acima, não dá para tomar um determinado plano como se fosse definitivo. Não dá para pensar que, pelo fato de termos elaborado, quer seja o plano de aula, de ensino ou o PPP, pura e simplesmente pode-se "fechar os olhos" e impô-los à realidade. Sempre é preciso verificar se aquilo que foi planejado confere e é adequado à realidade para a qual foi pensado e elaborado inicialmente. Isto não significa que na prática a teoria é outra. Não, pelo contrário, é necessário que a teoria dê conta da realidade concreta, com sua contradições, seus imprevistos, suas surpresas, seus movimentos e, se for necessário, ao colocar o plano em prática, recuar, rever, readequar, modificar. $\mathrm{Na}$ elaboração do planejamento, ainda que quem o elabora seja um agente concreto, o centro da preocupação não deve ser quem o elabora, mas sim, a realidade concreta, ou então, ao elaborar o planejamento sempre deve-se levar em conta a dinâmica da realidade.

Ao pensar no plano de ensino, o professordeve ter presente que ele se constitui num rol de conteúdos, atividades, ações, organizadas numa sequência lógica e contínua, que pressupõe formas de trabalho, estratégias de ação, objetivos geral e específicos, articulados entre si. Em função disso, também é necessário ter presente que cada unidade de ensino, cada aula específica se constitui na continuidade dos conteúdos que foram trabalhados anteriormente, que no conjunto visam à concretização do plano de ensino como um todo.

Como dissemos, a elaboração de um determinado planejamento envolve diversos elementos, passos e questões. Ainda que cada plano de aula esteja voltado para o desenvolvimento de um determinado tópico, para uma unidade temática específica, para um elemento do plano de ensino, ele também deve explicitar o conteúdo, os objetivos geral e específico, as estratégias de ação e o tipo de avaliação que, por sua vez, devem (estes elementos todos) trazer presente, expressar com bastante clareza, a concepção de educação, de homem e de sociedade, assim como os fins a que o mesmo se propõe.

Depois de elaborado o plano de ensino, é hora de trabalhar os tópicos específicos de cada aula, as unidades temáticas. Mas, vejamos, portanto, o que deve compreender um plano de trabalho docente. Por exemplo:

a) Definição do Tema da aula - $O$ que trabalhar? O tema da aula não deve ser escolhido aleatoriamente, "quem o determina é o plano de ensino". Dele se extrai um dos elementos (tópicos) para serem trabalhados num ou vários dias de aula. Por exemplo, podemos tomar o tema Família. 
b) Justificativa - Porque trabalhar tal tema? Isto tem a ver com o porquê da escolha de tal tema e não de outro, a importância que o mesmo tem para integrar o conjunto de temas arrolados no plano de ensino. Por exemplo, por que é um tema básico e fundamental para compreender outros; devido à necessidade de aprofundamento; devido à sequência dos conteúdos; devido à necessidade de compreensão da sociedade, e a importância que o mesmo tem na relação ensino-aprendizagem.

c) Objetivos - $O$ que se pretende com tal tema ou com tal conteúdo? Uma vez definido, são traçados os objetivos, ou seja, explicita-se o que se pretende ao trabalha-lo. Sempre é importante definir tanto o objetivo geral, que, como o nome já indica, é amplo e abrangente, como os objetivos específicos, que envolvem o detalhamento que visam dar cumprimento ao objetivo geral.

Objetivo geral: conhecer em que consiste a família e qual é seu papel e sua função na sociedade atual.

Objetivos específicos: 1) Compreender como é formada e composta a família em que vivemos; 2) refletir sobre os papéis sociais exercidos pelos membros da família; 3 ) conhecer os vários tipos de famílias existentes ao longo da história (monogâmica, poligâmica, nuclear, matriarcal, patriarcal, etc) e nas diversas sociedades (ocidentais, árabes, indígenas, etc); 4) analisar como são produzidos os bens necessários à sobrevivência da família; 5) analisar as diferentes condições em que vivem as famílias; 6) compreender por que a família é tida como a célula mater da sociedade; 7) compreender as relações entre a família e a propriedade.

d) Conteúdos - Quais os elementos que devem ser trabalhados? Os conteúdos devem ser definidos a partir da escolha do tema e da definição dos objetivos. Eles já indicam o que deve ser trabalhado para dar conta dos objetivos traçados. Por exemplo: 1) a composição da família; 2) os papéis sociais exercidos pelos membros da família; 3) os vários tipos de famílias; 4) a produção da sobrevivência da família; 5) a família ao longo da história; 6) as condições de vida da família; 7) a família como núcleo básico fundamental da sociedade e suas implicações; 8) a família situada na sociedade capitalista.

e) Estratégias de trabalho ou metodologia - Como serão trabalhados os conteúdos? De acordo com a questão ou o tema a ser trabalhado, assim como dos objetivos traçados, também deve-se adotar uma determinada estratégia. Cada objetivo exige uma estratégia adequada. Por exemplo, para atingir os objetivos acima, pode-se iniciar perguntando sobre a procedência, a origem, a raça a que cada um dos alunos pertence. Em seguida, pode-se realizar um diálogo mediado pelo professor, para ver se há diferentes compreensões sobre o que se entende por família. Caso se verifique isso, procurar explicitar essas diferenças e, caso não apareçam, o professor pode instigá-los a relatar outros tipos de que já viram ou ouviram falar, e trabalhar a ideia de que na sociedade nem todas as famílias são iguais, assim como também os indivíduos são diferentes. Para compreender melhor as diferenças entre elas e os papéis exercidos socialmente, pode-se solicitar aos alunos que tragam para aula fotos de suas famílias. Pode-se pedir para que cada um se desloque para frente dos demais colegas, apresente, fale, comente sobre sua família, sua composição, o papel exercido pelos seus membros, as condições em que vivem, os locais de trabalho, a procedência. Com os dados de salários, número de membros, gastos com alimentação, transporte, aluguel, vestuário, despesas com lazer, saúde, educação etc, pode-se trabalhar as operações matemáticas. Estas, por sua vez, podem ajudar a refletir e compreender as condições sociais e o funcionamento da sociedade. A partir do local de moradia, da procedência das famílias, dos motivos que as 
levaram a viver / morar onde moram. Por exemplo, pode-se trabalhar sobre a localização geográfica, as condições de vida, os conflitos sociais e a história. Além disso, pode-se organizar uma exposição com as fotos trazidas pelos alunos; pode-se estimular para que desenhem ou escrevam uma redação sobre como vêem sua família, ou como gostariam que fosse e depois comentar, discutir e debater com eles sobre as semelhanças, diferenças, especificidades, condições de vida, os diferentes tipos de famílias, as diferenças sociais, bem como sobre os conflitos decorrentes das diferenças...

Assim, ao mesmo tempo em que se trabalha o conteúdo da aula propriamente dito, pode-se discutir sobre a história de vida e da sociedade, ensinar a ler e a escrever corretamente, estimular a integração entre os alunos, possibilitar a compreensão, a reflexão sobre a sociedade e a luta contra as desigualdades sociais, os preconceitos, além de ajudar os alunos a desenvolverem a oralidade e a escrita, exercitar sua autonomia. Em relação à dinâmica de trabalho, além das já mencionadas, também pode-se realizar trabalhos em grupo, debates etc.

f) avaliação - Tem a ver com a relação dos conteúdos, com a forma e os objetivos estabelecidos. A avaliação não deve se limitar aos alunos, muito menos a atribuir a responsabilidade e justificativa da não aprendizagem aos alunos. Deve, ao mesmo tempo, possibilitar a verificação se o aluno atingiu os objetivos esperados e também servir para que o professor reflita sobre o trabalho que realiza, sobre a necessidade ou não de retorno ao tema, verificar se os conteúdos, a forma e os meios foram adequados à idade, à etapa de desenvolvimento, ou se há necessidade de rever e mudar a forma de trabalho e até mesmo os conteúdos.

Devido à característica da Educação Infantil e dos anos iniciais do Ensino Fundamental, devido ao fato de um mesmo professor trabalhar com todos os conteúdos de um determinado ano, ele também pode trabalhar todos os conteúdos de forma indissociada, de forma articulada, sem necessidade de se organizar, por exemplo, por aulas isoladas e separadas por disciplinas (história, geografia, matemática, língua portuguesa, ciências...) ou por áreas do conhecimento de forma fragmentada. Como vimos, uma mesma questão / tema / problema permite articular todos os conteúdos das diferentes áreas do conhecimento ao mesmo tempo. Isto, porém, exige que o professor tenha presente e domine todos os conteúdos da série, de tal modo que, de acordo com a ocasião e a necessidade, permita-lhe transportar-se de um conteúdo a outro, de uma "disciplina a outra", de uma "área a outra". Colocamos entre aspas, pois, desta forma significa que o centro encontra-se na aprendizagem, no conhecimento, entendido como um todo.

Neste texto, tomamos apenas um exemplo de conteúdo e como ele pode ser trabalhado tendo em vista uma determinada concepção de educação. Todavia, todos os conteúdos podem ser pensados e trabalhados de forma assemelhada, assim como as formas e as estratégias de se trabalhar. Fica aí o desafio de se pensar e fazer uma educação diferente, para uma nova sociedade.

Ao longo do texto chamamos a atenção para o fato de que o planejamento deve ser um ato consciente e reflexivo; deve ser flexível e permitir adequações quando necessárias. Ainda que o planejamento tenha sempre a mesma forma, seja composto pelos mesmos elementos, não pode ser pensado como uma forma, como uma espécie de carimbo que se imprime de igual modo em diferentes situações, condições e conteúdos. O planejamento também muda de acordo com a compreensão que temos da educação, do homem e da sociedade, isto é, com a mudança de sociedade e de época. Da mesma forma que ele precisa ser pensado a partir de cada situação ou questão específica a ser trabalhada, dos 
objetivos pretendidos. Assim pode-se explicar porque, ao longo da história, por exemplo, tivemos diferentes tendências educacionais (Escola Tradicional, Nova, Tecnicista e Crítico-Social dos conteúdos - Histórico-Crítica)e, portanto, também diversas compreensões sobre o planejamento, ou seja, tivemos diversas formas de compreender os conteúdos, os objetivos, os métodos, a avaliação, bem como, os alunos, os professores, a educação e a sociedade. A compreensão do planejamento também muda com a época, o local e a sociedade. Um bom planejamento deve dar conta disto.

\section{Ilustração}

Uma determinada pessoa decidiu construir uma casa. Confiando na sua experiência, saiu a procurar um terreno que julgava adequado à satisfação de suas necessidades, quais sejam, encontrar um espaço que permitisse a construção de uma casa de aproximadamente 220 metros e que ainda tivesse um espaço para o cultivo de um pequeno pomar, a organização de um canteiro de temperos e algumas verduras, além de possibilitar fazer um pequeno jardim. Após percorrer a cidade e analisar diversas opções, conjugá-los com os preços e com as necessidades, encontrou um todo murado, com muitas árvores frutíferas (abacates, laranja baia, laranja trepadeira, limão siciliano, mexerica, lima, nozes, seriguela, caqui, pêssego, além de um pé de cipreste, outro de uva japonesa e até uma araucária), com uma área de $15 \mathrm{~m} 2$ x 55m2, que julgou belíssimo e adequado.

Impressionado com o tamanho, com as árvores e com a localização, adquiriu o terreno. Logo, contatou com um arquiteto, trocou algumas ideias sobre a estrutura da casa, o que pretendia, suas necessidades e solicitou a elaboração de um projeto. Depois de analisa-lo, pediu para que fossem feitas algumas alterações e, após isso, solicitou que fosse feita a planta definitiva. Contudo, quando o projeto ficou pronto, deu-se conta de que a execução do projeto implicava no corte da grande maioria das árvores; percebeu que o terreno tinha uma inclinação e ficava num nível abaixo da calçada da rua, fato esse que inicialmente não passou pela sua preocupação, mas que, de acordo com os engenheiros, não seria adequado construir uma casa abaixo do nível da rua, pois, além do problema de estética, também havia o problema de inundação. Assim, para ficar numa posição adequada necessitaria fazer um muro de arrimo e aterrar, o que exigia a colocação de aproximadamente 70 caminhões de terra; percebeu também que os muros que cercavam o terreno, que pareciam ser um fato positivo, na verdade tinham sido erguidos sem estrutura e estavam todos tortos e exigiam que alguns recebessem reforços e outros fossem derrubados e refeitos.

Quando o projeto já estava pronto, quando já havia sido feita a derrubada das árvores, quando já havia construído o muro de arrimo e foi executar o projeto arquitetônico deu-se conta de que, ao invés do terreno ter $15 \mathrm{~m} 2$ de largura conforme havia adquirido e escriturado, tinha $14,60 \mathrm{~m} 2$ de frente e $15,40 \mathrm{~m} 2$ no fundo, o que implicava em reelaborar o projeto ou diminuir as medidas do projeto existente para poder obter o alvará. Feito isso, no momento de fazer a perfuração para as estacas, contratou um especialista que iria fazer os buracos com um trator, ao custo de $\mathrm{R} \$ 1,80$ ao metro, mas ao iniciá-los, a cada $3 \mathrm{~m}$ de profundidade encontrava água. Isto o obrigou a contratar outra empresa para realizar o mesmo trabalho com um bate-estaca, mas ao custo de $\mathrm{R} \$ 7,50$ ao metro. Além disso, quando a empresa já estava finalizando o serviço, ao fazer os buracos próximos da casa de um dos vizinhos, o impacto das pancadas para perfurar os buracos começou a provocar rachaduras na casa, obrigando assim a parar o trabalho e fazê-lo manualmente. Este foi o 
percurso realizado numa primeira etapa da execução do projeto da casa do Sr. Carlos Alberto.

O exemplo acima permite extrair algumas reflexões:

a) Este exemplo demonstra que o planejamento não só é necessário como não pode ser desprezado. Além disso, exige que seja reavaliado e readequado a cada momento.

b) Demonstra que o planejamento inicial não foi feito de forma adequada a partir de um estudo prévio e detalhado da realidade existente.

c) Demonstra que para fazer planejamento não basta confiar na experiência, nos conhecimentos que se tem e na boa vontade.

d) Ao fazer um planejamento, é necessário ter presente e, inclusive, deixar espaço para possíveis imprevistos; prevê-los e também arcar com as consequências.

e) Para obter êxito no planejamento, é necessário muita atenção ao que se faz; transformar-se num estudioso permanente de todo o processo e ser capaz de ir avaliando os passos a serem dados e os resultados que vão sendo obtidos.

d) Ao elaborar um determinado planejamento, um determinado projeto. é necessário e fundamental ter presente a realidade compreendida em cada momento do processo. Mesmo que a realidade e a compreensão que tenhamos dela mudem constantemente e exijam que o planejamento inicial seja alterado, torna-se necessário planejar. Pois, sempre procuramos fazer o melhor plano a partir do conhecimento e as condições que temos, mas como não temos o controle de todas as variáveis e não conhecemos toda a realidade, faz-se necessário fazer ajustes aos projetos sempre que compreendemos melhor a realidade, ou então, sempre que percebemos novos problemas ou desafios que não havíamos nos dado conta anteriormente quando iniciamos o planejamento. Ou seja, pode-se dizer que as adequações não são decorrentes da realidade exterior, mas sim de nós mesmos, da nossa incapacidade de conhecer e agir adequadamente sobre ela. Deste modo, como dissemos, é necessário fazer planejamento, mas não tomá-lo como pronto, acabado e definitivo; é preciso estar aberto à realidade e alterar o projeto de acordo com a exigência dela, a cada momento, tendo em vista o bom resultado do projeto.

\section{REFERÊNCIAS BIBLIOGRÁFICAS}

BORDENAVE, Juan Díaz e PEREIRA, Adair Martins. Estratégias de EnsinoAprendizagem. 14ª edição, Petrópolis: Vozes, 1994.

FREIRE, P. E ILLICH, I. Diálogo. Buenos Aires: Búsqueda, 1975.

HARPER, B. e ourtros. Cuidado escola. São Paulo: Brasiliense, 1980.

LIBÂNEO, José Carlos. Didática. São Paulo: Editora Cortez, 1994. ( Coleção Magistério $\left.2^{\mathrm{a}} \mathrm{Grau}\right)$.

PILETTI, Claudino. Didática Geral. São Paulo: Ática, 1986.

TURRA, Clódia Maria Godoy, SANT’ANNA, Flávia Maria, ENRICONE, Délcia e ANDRÉ, Lenir Cancella. Planejamento de Ensino e Avaliação. 11 ${ }^{\text {a }}$ edição, Porto Alegre: Sagra-dc Luzzatto editores, 1996. 
VIANNA, Ilca Oliveira de Almeida. Planejamento Participativo na Escola. São Paulo: EPU, 1986.

\footnotetext{
${ }^{1}$ Publicado aqui com algumas adequações em: ESTRADA, A. A; MALACARNE, V; ORSO, P. J. e FIUZA, A. F. Pesquisa, Educação e Relações sociais. Cascavel. Edunioeste, 2012, pp. 25-47.

2 Doutor em História e Filosofia da Educação pela Unicamp, docente do Curso de Pedagogia e do Mestrado em Educação da Unioeste, Líder do Grupo de Pesquisa em História, Sociedade e Educação no Brasil - GT da Região Oeste do Paraná - HISTEDOPR.
} 